\title{
European Association of Clinical Anatomy-International Symposium of Clinical and Applied Anatomy. Online Congress: Save the Dates: September 2021, 14-16
}

๑) Springer-Verlag France SAS, part of Springer Nature 2021

Dear Colleagues,

It is my pleasure to announce that the 16th Congress of the European Association of Clinical Anatomy (EACA) will be held ONLINE jointly with the XII Meeting of the International Symposium of Clinical and Applied Anatomy (ISCAA) from 14 to 16th September 2021. EACA and ISCAA congresses are successful events that periodically permit to all the students, teachers and researchers interested in Clinical Anatomy to meet and to exchange information. Year after year, EACA meeting has become a dynamic forum for anatomy professors from all over the world and students to share their knowledge with each other, and we are very honoured to host the $16^{\circ}$ EACA meeting jointly with the XII ISCAA meeting in Padova in 2021. Unfortunately, due to the Coronavirus, we had to reschedule the meeting in an online event, but we think that is important to maintain the congress, even if in another format. Consequently, we have decided to create this new program, totally online. The congress is planned to be held in 3 days, during which you can attend to main lectures, communications, eight symposia and e-posters. The main topics will be clinical anatomy, neuroanatomy and education. As usual, a large part of the meeting will provide opportunities for delegates to update colleagues of developments in all the traditional topics of clinical anatomy and of the technological innovations that are more relevant for anatomy education.

The website will soon open for registration and submissions.

It will certainly be a great cultural and scientific event and a further opportunity to discuss issues of mutual interest with many colleagues from across Europe.

Professor Raffaele De Caro

President of 16th Congress of EACA

held jointly with XII Meeting of ISCAA

Publisher's Note Springer Nature remains neutral with regard to jurisdictional claims in published maps and institutional affiliations. 